\title{
DEVELOPMENT OF HFU-BASED PERMEABILITY PREDICTION MODELS USING CORE DATA FOR CHARACTERISATION OF A HETEROGENEOUS OLIGOCENE SAND IN THE NAM CON SON BASIN
}

\author{
Nguyen Van Hieu', Nguyen Hong Minh', Phan Ngoc Quoc', Pham Huy Giao ${ }^{1,2}$ \\ 'Vietnam Petroleum Institute (VPI) \\ ${ }^{2}$ PetroVietnam University (PVU) \\ Email: hieunv@vpi.pvn.vn \\ https://doi.org/10.47800/PVJ.2021.10-03
}

\section{Summary}

Core data by both routine and special core analysis are required to understand and predict reservoir petrophysical characteristics. In this research, a total number of 50 core plugs taken from an Oligocene sand in the Nam Con Son basin, offshore southern Vietnam, were tested in the core laboratory of the Vietnam Petroleum Institute (VPI).

The results of routine core analysis $(\mathrm{RCA})$ including porosity and permeability measurements were employed to divide the study reservoir into hydraulic flow units (HFUs) using the global hydraulic elements (GHEs) approach. Based on five classified HFUs, 16 samples were selected for special core analysis, i.e., mercury injection capillary pressure (MICP) and grain size analyses for establishing non-linear porosity-permeability model of each HFU based on Kozeny-Carman equation, which provides an improved prediction of permeability $\left(\mathrm{R}^{2}\right.$ $=0.846)$ comparing to that by the empirical poro-perm relationship $\left(R^{2}=0.633\right)$.

In addition, another permeability model, namely the Winland R35 method, was applied and gave very satisfactory results $\left(R^{2}=\right.$ 0.919). Finally, by integrating the results from MICP and grain size analyses, a good trendline of pore size distribution index $(\lambda)$ and grain sorting was successfully obtained to help characterise the study reservoir. High $\lambda$ came with poor sorting, and vice versa, the low $\lambda$ corresponded to good sorting of grain size.

Key words: Core analysis, hydraulic flow units (HFU), non-linear poro-perm, Oligocene sand, Nam Con Son basin.

\section{Introduction}

Many essential parameters to understand reservoir characteristics are derived from a series of core analysis, from core testing, routine core to special core analysis. The aim of this study is to find out a number of relevant relationships between different petrophysical parameters based on the core testing data to help predict permeability, pore size distribution and grain sorting for a reservoir. Nam Con Son basin (Figure 1) is the second largest hydrocarbon basin after Cuu Long basin, and the biggest natural gas producing basin in Vietnam. While oil production continually declines in Cuu Long, the exploration and production activities in Nam Con

Date of receipt: 5/7/2021. Date of review and editing: 5/7 - 30/9/2021 Date of approval: $7 / 10 / 2021$
Son play an important role for the oil and gas industry of the country. Unfortunately, the clastic reservoirs in this basin are often found heterogeneous, in particular the Oligocene sands, therefore finding good non-linear permeability prediction models is an important task.

In this study, core plugs were taken from conventional cores collected in Oligocene sandstone. Each core plug has 1.5 " diameter and approximately 2 " length. After the samples were trimmed to get the right cylinder shape, the cores were cleaned to remove any salt or hydrocarbon contents, and dried in a humidity oven for at least 48 hours at $60{ }^{\circ} \mathrm{C}$ and $40 \% \mathrm{RH}$ to preserve sensitive clay minerals. When the drying process was completed, the samples were stored in desiccators to avoid vapour absorption. Core testing including porosity, permeability, MICP and grain size measurements was conducted. 
The porosity was measured by UltraPore- $300^{\mathrm{TM}}$ and CMS-300 equipment using the Boyle's Law gas expansion method.

Gas (nitrogen) permeability was determined using gas permeameter (GasPerm) equipment. Firstly, the sample was pushed in the core holder and confined, then nitrogen was passed through the sample at a known flow rate. Upstream pressure and flow rate were monitored until stable indicating steady-state conditions. Permeability using Darcy's equation was calculated from these data.

Mercury injection capillary pressure (MICP) was performed on Autopore IV equipment, the sample was initially filled with mercury under a vacuum and was incrementally pressurised to a maximum of 60,000

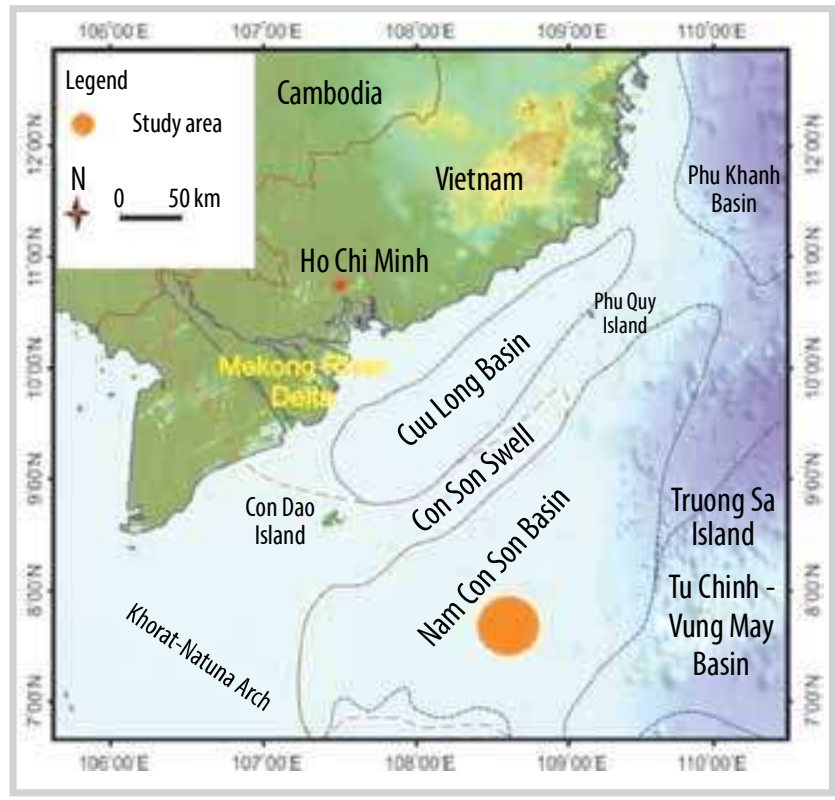

Figure 1. Study location in the Nam Con Son basin, Vietnam [1]. psia. The volume of mercury injected was determined by the change in capacitance in the capillary stem. This equipment can detect pore diameter range from approximately $0.002 \mu \mathrm{m}$ to $360 \mu \mathrm{m}$.

The grain size analysis was also conducted during thin section analysis. Based on standard deviation $(\sigma 1)$ of grain size, the grain sorting of each sample was classified to three main types as poorly, moderately, or well-sorted.

\section{Methodology}

\subsection{Core preparation}

A total of 50 core plugs were taken and their porosity and permeability were measured, based on which the target reservoir was divided into five hydraulic flow units by Global Hydraulic Elements method. Subsequently, 16 samples were selected from the identified HFUs for MICP and grain size analyses (Figure 2).

\subsection{Presentation and analysis of core data}

\subsubsection{Empirical porosity-permeability (poro-perm) cross plot}

This is the most used porosity-permeability relationship, constructed by plotting the core-measured permeability (log $k$ ) versus porosity $(\Phi)$ values in a semilogarithmic scale. It is an empirical poro-perm model that can effectively predict the permeability based on core porosity measurements [2]. However, in reality most reservoirs are geologically heterogeneous and anisotropic, thus a simple empirical poro-perm model may not work well, and more complex porositypermeability models have been developed to help predict permeability, in particular for the uncored reservoir intervals. One of these non-linear models

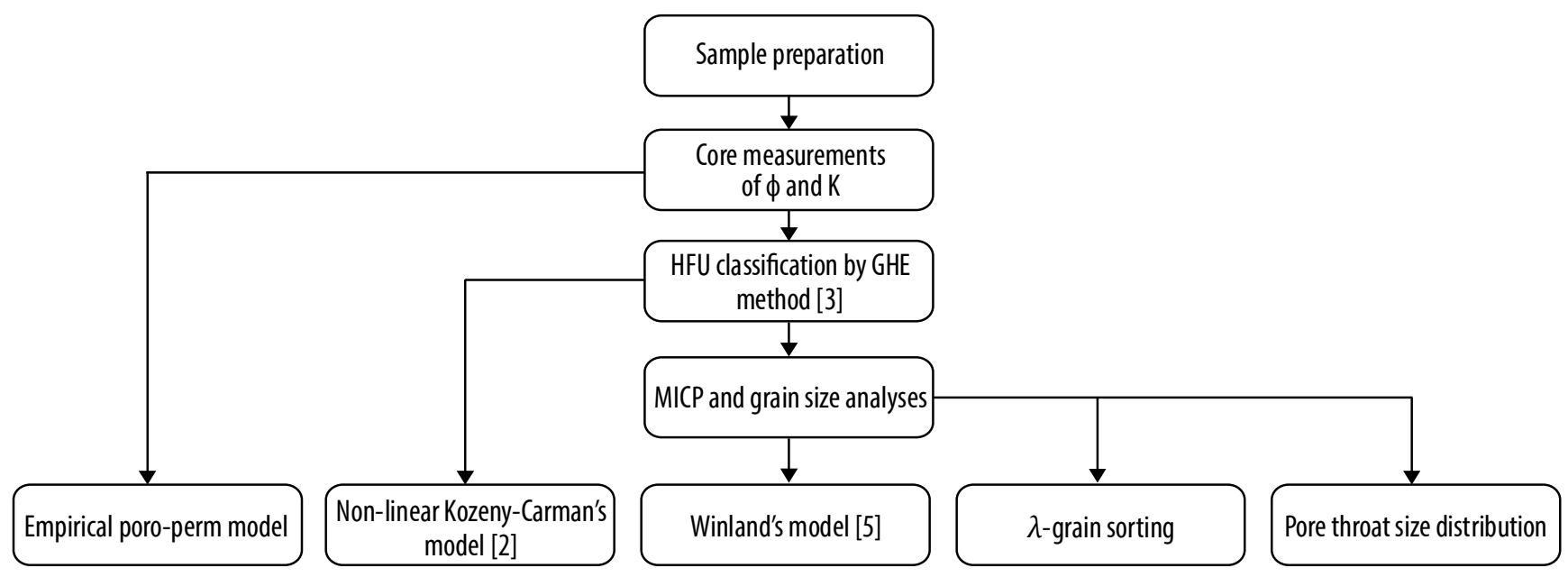

Figure 2. Flowchart of the study. 
Table 1. Hydraulic unit lower boundaries (shown as FZl values) for GHEs [3]

\begin{tabular}{|c|c|c|c|c|c|c|c|c|c|c|}
\hline FZI & 48.026 & 24.013 & 12.006 & 6.003 & 3.002 & 1.501 & 0.750 & 0.375 & 0.188 & 0.094 \\
\hline GHE & 10 & 9 & 8 & 7 & 6 & 5 & 4 & 3 & 2 \\
\hline
\end{tabular}

based on Kozeny-Carman Equation 2 is described in the following.

\subsubsection{Classification of HFU by GHE method [3]}

Hydraulic flow unit is a concept commonly used in petrophysics nowadays [2]. It is considered as a part of the reservoir where geological and petrophysical properties that affect the flow of fluid are consistent and predictably different from those of other parts of the same reservoir.

Corbett and Potter have developed a new technique of reservoir rock typing using the flow zone indicator (FZI) values [3]. They defined rock type and HFUs based on a series of ten FZI boundary values (Table 1).

The hydraulic quality of the rock is controlled by its pore geometry, which is a function of mineralogy and texture such as grain size, grain shape, sorting and packing as presented in Kozeny-Carman equation below [2]:

$$
K=\frac{1}{F_{s} \tau^{2} S_{g r}^{2}} \frac{\Phi_{e}^{3}}{\left(1-\Phi_{e}\right)^{2}}
$$

Where:

$\mathrm{K}$ is permeability, $\mu \mathrm{m}^{2}$;

$\mathrm{F}_{\mathrm{s}}$ is the shape factor;

$\tau$ is tortuosity;

$\mathrm{S}_{\mathrm{gr}}$ is the specific surface area per unit grain volume, $\mu \mathrm{m}^{-1}$;

$\Phi_{\mathrm{e}}$ is effective porosity, frac.

Taking square root of both sides of Equation 1 one gets:

$$
\sqrt{\frac{K}{\Phi_{e}}}=\left(\frac{1}{\sqrt{F_{s}} \tau S_{g r}}\right)\left(\frac{\Phi_{e}}{1-\Phi_{e}}\right)
$$

Denoting: $\sqrt{\frac{K}{\Phi_{e}}=R Q I}$ is reservoir quality index; $\frac{1}{\sqrt{F_{s}} \tau S_{g r}}=F Z I$ is flow zone indicator that represents textural characteristics of the reservoir; $\frac{\Phi e}{1-\Phi e}=\Phi_{z}$ is normalised porosity, which is the ratio between pore volume and grain volume.

Substituting RQI, FZI and $\Phi_{z}$ into Equation 2 one has:

$$
F Z I=\frac{R Q I}{\Phi_{Z}}
$$

Finally, Equation 1 can be rewritten as below to allow the permeability calculation of each HFU:

$$
K=1014 \times F Z I_{\text {avg }}^{2} \times \frac{\Phi_{e}^{3}}{\left(1-\Phi_{e}\right)^{2}}
$$

where $\mathrm{FZI}_{\mathrm{avg}}$ is the average $\mathrm{FZI}$ value of each HFU; Equation 4 is the permeability model based on KozenyCarman equation; 1014 is a constant to convert the permeability unit from $\mu \mathrm{m}^{2}$ to millidarcy (mD).

\subsubsection{Pore throat size calculation}

Pore throat size distribution of reservoir rock offered a promised understanding of fundamental flow processes in the porous matrix. It is, therefore an important parameter that reflects the reservoir quality. For instance, one rock containing the majority of the macro pore throat size suggests it may be a highly permeable rock and vice versa. Based on MICP data, pore throat size can be calculated directly from Washburn equation as below [4]:

$$
\begin{aligned}
& P_{c}=\frac{2 C \sigma \cos (\theta)}{r_{c}} \\
& r_{c}=\frac{P_{c}}{2 C \sigma \cos (\theta)}
\end{aligned}
$$

where $P_{c}$ is the capillary pressure, psi; $C$ is the Washburn constant (0.145038); $\sigma$ is the interfacial tension (Air-Hg), dynes/cm (485); $\theta$ is the contact angle (Air-Hg), degrees (140); and $r_{c}$ is the pore throat radius, $\mu \mathrm{m}$.

\subsubsection{Pore size distribution index $(\lambda)$}

The pore size distribution index $(\lambda)$ is a key parameter for characterisation of a heterogeneous porous medium, which has a strong influence on the capillary pressure shape curves as shown by Brooks-Corey's equation [5] below:

$$
P_{c}=P_{d}\left(\frac{S_{w}-S_{w i r}}{1-S_{w i r}}\right)^{\frac{-1}{\lambda}}
$$

Taking the logarithm of both sides of Equation 6 one gets:

$$
\ln \left(P_{c}\right)=\ln \left(P_{d}\right)+\left(\frac{-1}{\lambda}\right) \ln \left(\frac{S_{w}-S_{w i r}}{1-S_{w i r}}\right)
$$

where $P_{c}$ is capillary pressure, $p s i ; P_{d}$ is the entry (displacement) capillary pressure, psi; $\lambda$ is the pore size 
distribution index; $\mathrm{S}_{\mathrm{w}}$ is the water saturation (frac); $\mathrm{S}_{\text {wir }}$ is the irreducible water saturation (frac); $\left(\frac{S_{w}-S_{w i r}}{1-S_{w i r}}\right)$ is is the normalised water saturation.

By plotting the values of $\mathrm{P}_{c}$ versus the normalised water saturation on a log-log scale following Equation 7 one will get a straight line having the slope equal to $(-1 / \lambda)$, and the intercept of $\ln \left(P_{d}\right)$. This represents the basis of a graphical procedure to determine the pore distribution index.

\subsubsection{Pore throat radius (R35) and Winland' R35 approach}

R35 is the pore throat radius value corresponding to $35 \%$ mercury saturation from mercury injection capillary pressure test. Winland [5] suggested that the effective pore system that dominates flow through rock corresponds to a mercury saturation of $35 \%$ as shown in Equations $8 \mathrm{a}$ and $8 \mathrm{~b}$, and the producing capacity of each pore throat group is shown in Table 2:

$\log (R 35)=0.732+0.588 \log (k)-0.864 \log (\Phi)(8 a)$

$\log k=\frac{1}{0.588}[0.732-0.864 \log (\Phi)-\log (R 35)](8 \mathrm{~b})$

\section{Results and discussion}

\subsection{Empirical porosity-permeability relationship}

Measurements of permeability and porosity of all 50 samples are plotted in Figure 3, giving a poroperm relationship as shown in Equation 9 with $\mathrm{R}^{2}=$ 0.633:

$$
K=2.54 \times 10^{-5} \times e^{73.65 \Phi_{e}}
$$

\subsection{Hydraulic flow unit identification and permeability prediction}

Figure 4 shows a plot of RQI versus $\Phi_{z^{\prime}}$ based on which five discrete rock types were identified and supposed to correspond to five HFUs, having the average $\mathrm{FZI}$ equal to $0.115,0.287,0.481,1.048$ and 2.324 , respectively (Table 3 ). It is clearly seen that the higher FZI the better reservoir quality in terms of fluid flow in the reservoir rock. For each HFU, the permeability can be calculated using the non-linear poro-perm model in Equation 4, which is plotted versus the measured permeability as shown in Figure 5 , showing a good $R^{2}=0.846$.
Table 2. Production capacity based on R35 [5]

\begin{tabular}{|c|c|c|}
\hline Port size & R35 value $(\boldsymbol{\mu m})$ & \begin{tabular}{c} 
Production capacity (bbl/day) \\
\hline Mega
\end{tabular} \\
\hline Macro & 2 to 10 & Tens of thousands \\
\hline Meso & 0.1 to 2 & Thousands \\
\hline Micro & $<0.1$ & Hundreds \\
\hline
\end{tabular}

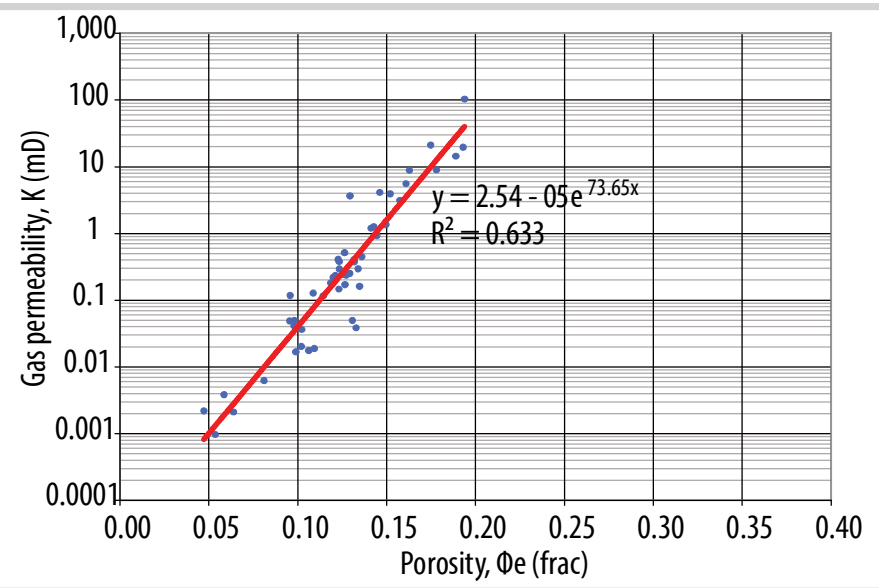

Figure 3. Empirical porosity - permeability model.

Table 3. Average FZI value of five identified HFUs

\begin{tabular}{|c|c|c|}
\hline Hydraulic flow unit & $\begin{array}{c}\text { Average flow zone } \\
\text { indicator, } \text { FZI }_{\text {avg. }}\end{array}$ & $\begin{array}{c}\text { Number of samples } \\
\text { of each HFU }\end{array}$ \\
\hline HFU1 & 0.115 & 12 \\
\hline HFU2 & 0.287 & 20 \\
\hline HFU3 & 0.481 & 7 \\
\hline HFU4 & 1.048 & 9 \\
\hline HFU5 & 2.324 & 2 \\
\hline
\end{tabular}

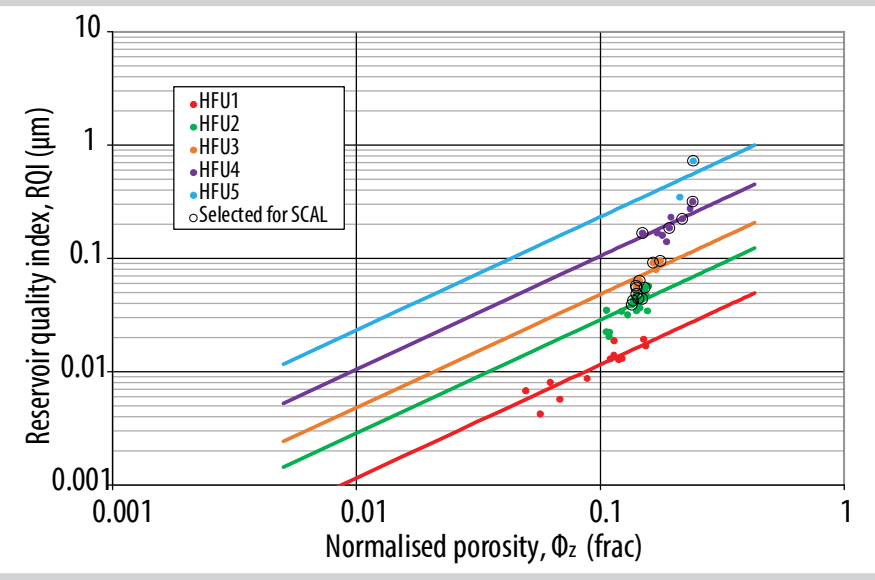

Figure 4. Identification of $5 \mathrm{HFU}$ s based on reservoir quality index (RQI) versus the normalised porosity $(\Phi)$ relationship.

\subsection{Results of mercury injection capillary pressure (MICP) and grain size analyses}

Among five classified HFUs, HFU1 has the lowest average FZI. It was considered a non-reservoir and eliminated in further reservoir characterisation. A total of 16 samples from HFU2,HFU3, 


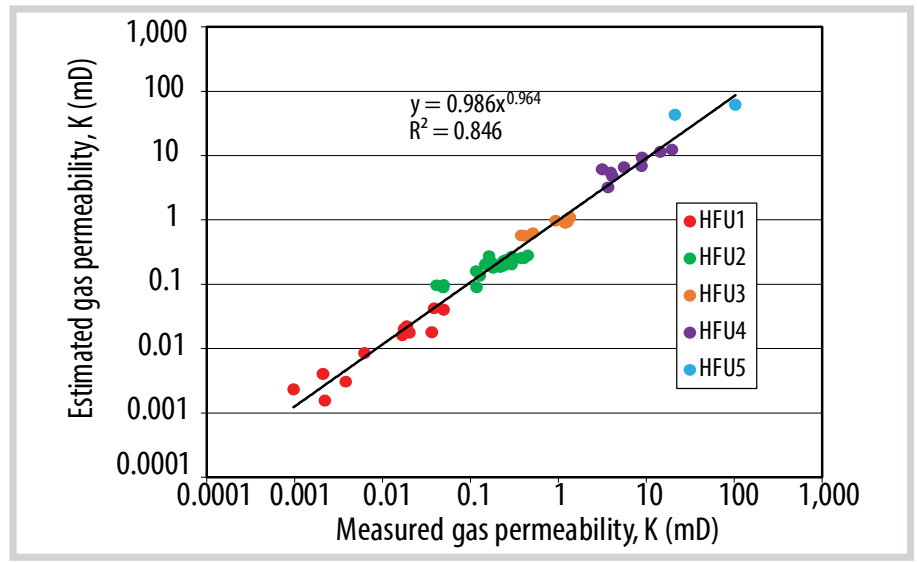

Figure 5. Measured permeability versus calculated permeability by Kozeny-Carman equation for five HFUs.

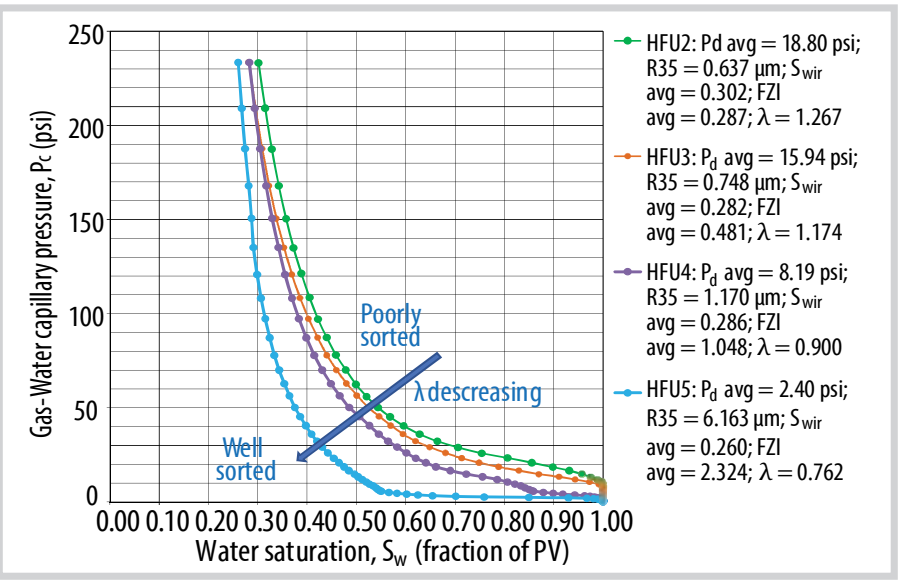

Figure 6. Capillary pressure curves for HFUs 2 to 5.
HFU4 and HFU 5 were selected for MICP and grain size analyses. The capillary pressure of the air-mercury system was converted to the gas-water system, and the approximately residual water saturation values were taken at $230 \mathrm{psi}$ of the gas-water system.

The summary of results is presented in Table 4, indicating that the grains of samples in HFU2 were poorly to moderately sorted, showing the highest average pore size distribution index $(\lambda=1.267)$, while most of the well-sorted samples in the HFU4 and HFU5 have lower $\lambda$ of 0.900 and 0.762 , respectively. On the other hand, most of the moderately to wellsorted samples in HFU3 $\lambda$ range from 1.116 to 1.264. By plotting capillary pressure versus water saturation as shown in Figure 6 with the changes in $\lambda$ and grain sorting [6], it can be observed that the samples with low $\lambda$ tend to be well-sorted, whereas those with larger $\lambda$ showed poorer sorting.

\subsection{Pore throat size distribution and $R 35$ value}

As seen in Figure 7, the pore throat sizes of all samples are broadly presented from macro to micro and smaller. Generally, the pore throat sizes of HFU2 and HFU3 vary from meso to micro and smaller, while those of HFU4 and HFU5 are found in a narrower range from macro to meso.

Table 4. Summary of MICP and grain size analyses results

\begin{tabular}{|c|c|c|c|c|c|c|c|c|c|c|c|c|}
\hline \multirow{2}{*}{$\begin{array}{c}\text { Sample } \\
\text { No. }\end{array}$} & \multirow{2}{*}{$\begin{array}{c}\text { Helium } \\
\text { porosity } \\
\text { frac }\end{array}$} & \multirow{2}{*}{$\begin{array}{c}\text { Gas } \\
\text { permeability } \\
\text { mD }\end{array}$} & \multirow[b]{2}{*}{$\mathrm{RQI}, \mu \mathrm{m}$} & \multicolumn{2}{|c|}{$P_{d}$} & \multirow[b]{2}{*}{ Lamda $(\lambda)$} & \multirow{2}{*}{$\begin{array}{c}\text { Correlation } \\
\text { coefficient } \\
\left(\mathbf{R}^{2}\right)\end{array}$} & \multirow[b]{2}{*}{$S_{\text {wir }}$ frac } & \multirow[b]{2}{*}{ R35, $\mu \mathrm{m}$} & \multirow[b]{2}{*}{ HFU } & \multicolumn{2}{|c|}{ Grain size analysis } \\
\hline & & & & Air-Hq, psi & Air-W, psi & & & & & & $\begin{array}{c}\text { Standard } \\
\text { deviation (01) }\end{array}$ & $\begin{array}{l}\text { Grain } \\
\text { Sorting }\end{array}$ \\
\hline 9 & 0.132 & 0.41 & 0.363 & 97.23 & 18.84 & 1.250 & 0.914 & 0.317 & 0.575 & 2 & 0.71 & M \\
\hline 11 & 0.129 & 0.25 & 0.295 & 110.13 & 21.34 & 1.322 & 0.918 & 0.303 & 0.533 & 2 & 0.66 & $M-W$ \\
\hline 12 & 0.120 & 0.22 & 0.311 & 92.48 & 17.92 & 1.237 & 0.920 & 0.303 & 0.681 & 2 & 0.72 & M \\
\hline 13 & 0.123 & 0.30 & 0.345 & 80.65 & 15.63 & 1.210 & 0.917 & 0.279 & 0.806 & 2 & 0.70 & M \\
\hline 14 & 0.119 & 0.18 & 0.289 & 108.06 & 20.94 & 1.310 & 0.924 & 0.348 & 0.518 & 2 & 1.33 & $P$ \\
\hline 16 & 0.125 & 0.25 & 0.308 & 93.66 & 18.15 & 1.272 & 0.930 & 0.261 & 0.706 & 2 & 0.64 & $M-W$ \\
\hline \multicolumn{3}{|c|}{ Average HFU2 } & 0.319 & 97.03 & 18.80 & 1.267 & & 0.302 & 0.637 & & & \\
\hline 3 & 0.141 & 1.20 & 0.557 & 67.77 & 13.13 & 1.161 & 0.912 & 0.239 & 1.026 & 3 & 0.41 & W \\
\hline 6 & 0.123 & 0.38 & 0.391 & 91.66 & 17.76 & 1.136 & 0.879 & 0.365 & 0.465 & 3 & 0.99 & $M C$ \\
\hline 7 & 0.126 & 0.52 & 0.439 & 83.75 & 16.23 & 1.190 & 0.912 & 0.287 & 0.742 & 3 & 0.64 & $M-W$ \\
\hline 8 & 0.150 & 1.36 & 0.538 & 71.44 & 13.84 & 1.116 & 0.902 & 0.273 & 0.833 & 3 & 0.69 & $M-W$ \\
\hline 10 & 0.123 & 0.41 & 0.410 & 96.60 & 18.72 & 1.264 & 0.919 & 0.245 & 0.673 & 3 & 0.62 & $M-W$ \\
\hline \multicolumn{3}{|c|}{ Average HFU3 } & 0.467 & 82.24 & 15.94 & 1.174 & & 0.282 & 0.748 & & & \\
\hline 1 & 0.178 & 8.98 & 1.029 & 38.50 & 7.46 & 0.852 & 0.873 & 0.298 & 1.044 & 4 & 0.49 & W \\
\hline 4 & 0.161 & 5.60 & 0.967 & 80.51 & 15.60 & 1.165 & 0.902 & 0.336 & 0.593 & 4 & 0.55 & $M-W$ \\
\hline 5 & 0.193 & 19.67 & 1.325 & 26.91 & 5.21 & 0.864 & 0.878 & 0.264 & 1.879 & 4 & 0.45 & W \\
\hline 15 & 0.129 & 3.67 & 1.125 & 23.12 & 4.48 & 0.721 & 0.809 & 0.248 & 1.166 & 4 & 0.49 & W \\
\hline \multicolumn{3}{|c|}{ Average HFU4 } & 1.112 & 42.26 & 8.19 & 0.900 & & 0.286 & 1.170 & & & \\
\hline 2 & 0.194 & 103.27 & 3.014 & 12.38 & 2.40 & 0.762 & 0.894 & 0.260 & 6.163 & 5 & 0.45 & W \\
\hline \multicolumn{2}{|c|}{ Average HFU5 } & & 3.014 & 12.38 & 2.40 & 0.762 & & 0.260 & 6.163 & & & A \\
\hline
\end{tabular}


Referring to Table 4, most of the R35 values of the HFUs 2 to 4 belong to the meso pore size groups with production capacity of hundreds $\mathrm{bbl} /$ day, except the HFU5 that has the highest R35 value of $6.163 \mu \mathrm{m}$ and is identified as macro pore with production capacity of thousands bbl/day.

Permeability predicted by the Winland's model (Equation $8 b$ ) matches well with the measured permeability values as seen in Figure 8 , showing good coefficient $\left(R^{2}=0.919\right)$.

From the results calculated by three permeability models as plotted in Figure 9, one can see that Kozeny-Carman's model and Winland's model gave a better correlation coefficient $\left(\mathrm{R}^{2}\right)$ compared to that by the empirical poro-perm model.

\section{Conclusions and recommendations}

Core tests were conducted over a set of 50 core plugs taken from the Oligocene sand in the Nam Con Son basin. Subject to the core analysis and interpretation results, the following conclusions were drawn:

- Based on the conventional RCA measurements of porosity and permeability, an empirical poro-perm model was successfully found for the study Oligocene sand (Figure 3 and Equation 9) with a correlation coefficient $\mathrm{R}^{2}$ $=0.633$ as reproduced below:

$$
K=2.54 \times 10^{-5} \times e^{73.65 \Phi_{e}}
$$

By applying the GHE method [3] the study clastic reservoir was divided into five hydraulic flow units (HFUs) denoted from HFU1 to 5 . For each of them, the following non-linear permeability prediction models were found using the modified Kozeny-Carman equation (Equation 4) as reproduced below:

$$
\begin{array}{ll}
K=1,014 \times 0.013 \times \frac{\Phi_{e}^{3}}{\left(1-\Phi_{e}\right)^{2}} & \text { for HFU1 } \\
K=1,014 \times 0.082 \times \frac{\Phi_{e}^{3}}{\left(1-\Phi_{e}\right)^{2}} & \text { for HFU2 }(1 \\
K=1,014 \times 0.232 \times \frac{\Phi_{e}^{3}}{\left(1-\Phi_{e}\right)^{2}} & \text { for HFU3 } \\
K=1,014 \times 1.099 \times \frac{\Phi_{e}^{3}}{\left(1-\Phi_{e}\right)^{2}} & \text { for HFU4 }\left(11 d^{2}\right. \\
K=1,014 \times 5.401 \times \frac{\Phi_{e}^{3}}{\left(1-\Phi_{e}\right)^{2}} & \text { for HFU5 }
\end{array}
$$

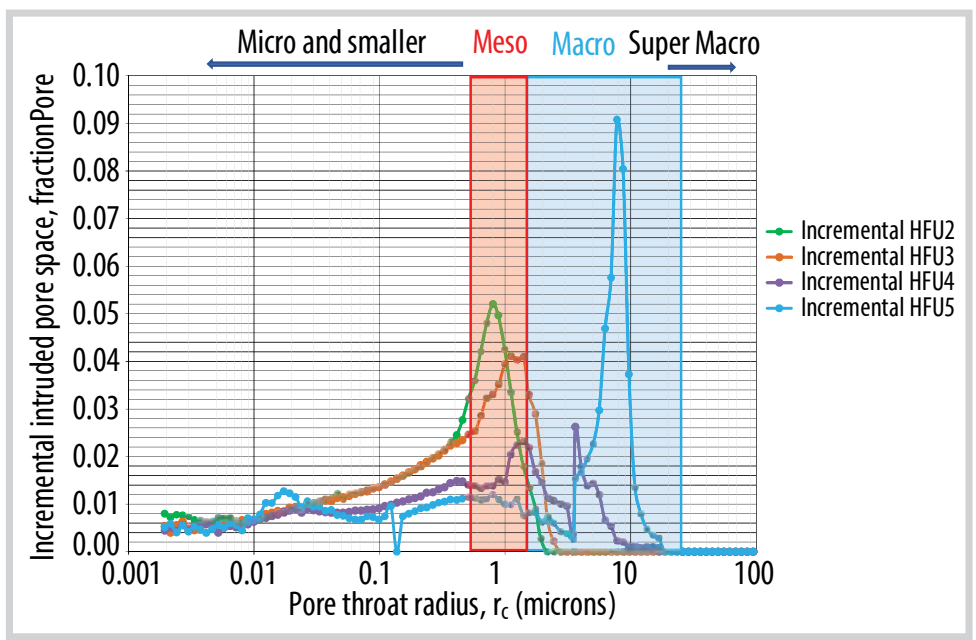

Figure 7. Pore throat size distribution for each HFU.

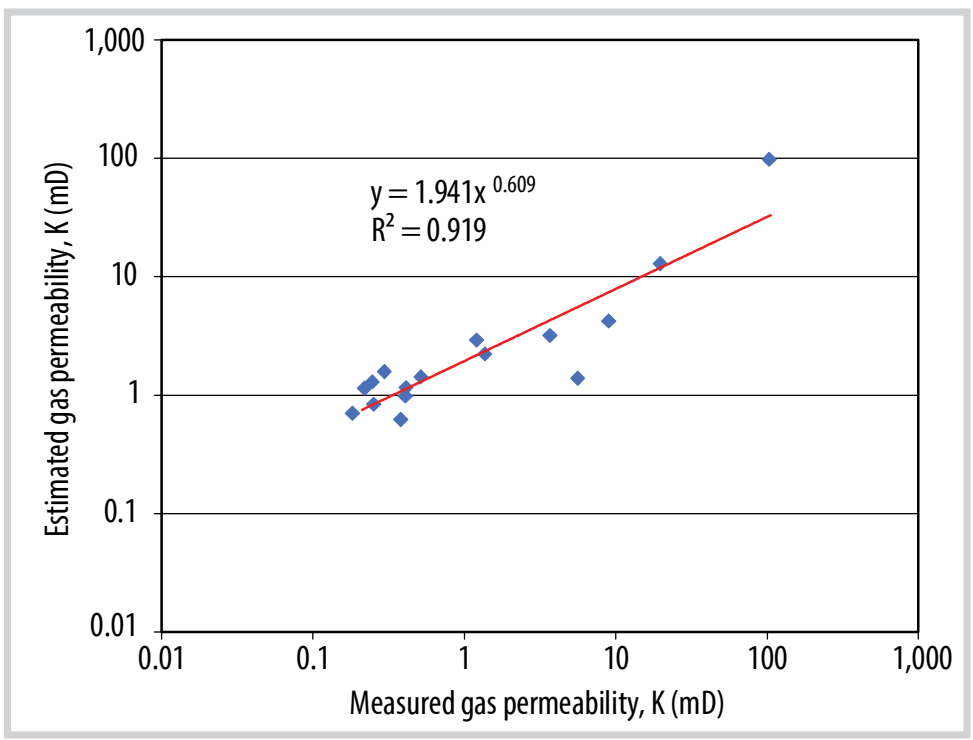

Figure 8. Measured permeability versus permeability calculated by Winland's equation (Equation 8b).

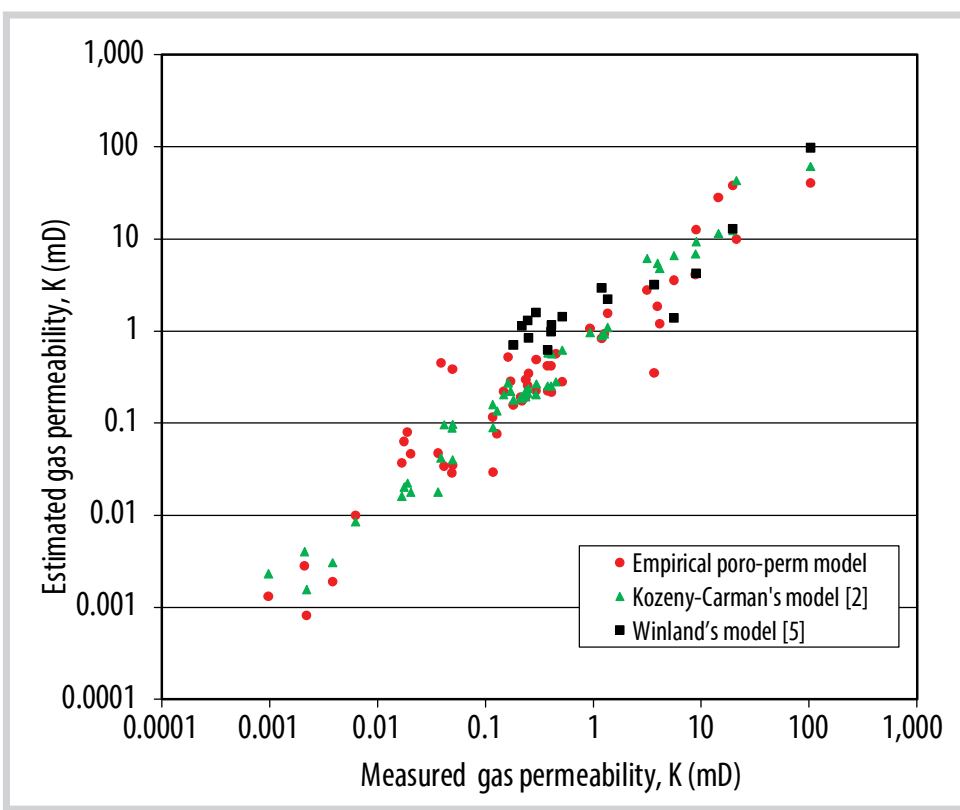

Figure 9. Comparison of three permeability prediction models developed in this study. 
By plotting the permeability calculated by Equations 11a-e and comparing with the measured permeability as shown in Figure 5, one can see an increase of $R^{2}$ to 0.846 , which is higher than that by the empirical model mentioned above with $\mathrm{R}^{2}=0.633$.

Among the five identified hydraulic flow units, HFU1 has the lowest average $\mathrm{FZI}$ and was considered as nonreservoir. A total of 16 samples were selected only from HFU2, HFU3, HFU4 and HFU5 for further SCALs of mercury injection of capillary pressure (MICP) and grain size analyses. It was found that most of the samples in HFU4 and HFU5 have pore throat size distributing in macro and meso size range, while HFU2 and HFU3 were meso and smaller. Consequently, another permeability prediction model based on Winland R35's equation (Equation 8a) was developed in this study using MICP results as follows:

$$
\log k=1.7[0.732-0.864 \log (\Phi)-\log R 35)]
$$

By plotting the permeability calculated by Equation $8 \mathrm{~b}$ or 12 and comparing with the measured permeability as shown in Figure 8 , one can see a significant improvement of $\mathrm{R}^{2}$ to 0.919 , which is higher than that by the empirical poro-perm with $\mathrm{R}^{2}=0.633$. Comparison of the 3 permeability models is shown in Figure 9, illustrating clearly the advantages of HFU-based nonlinear permeability to the empirical poro-perm for an Oligocene sand in the Nam Con Son basin.

- It was found that grain sorting of the study Oligocene sand is closely related to the pore size distribution index $(\lambda)$, i.e., the low $\lambda$ corresponds to wellsorted grains, while the high $\lambda$ corresponds to more heterogeneity and poorly sorted grains. Based on the R35 values, the HFU2, HFU3 and HFU4 are of meso pores, while HFU5 is of macro pore. The latter, therefore, can produce hundreds to thousands barrels/day.

- As the HFU-based permeability prediction method based on Kozeny-Carman equation proved to be effective in the characterisation of a heterogeneous Oligocene sand in this study, we recommend it be applied to other clastic reservoirs and fields in the Nam Con Son basin. It is also recommended to revisit the values of $\mathrm{FZI}$ used in HFU classification by the GHE method [3] (Table 3), taking into account the local geological conditions.

\section{Acknowledgements}

Acknowledgments are due to the data support given by the Vietnam Petroleum Institute (VPI) and the technical assistance by the Vietnam National Foundation for Science and Technology Development (NAFOSTED) under the grant number 105.99-2019.324.

\section{References}

[1] Pham Huy Giao, Pham Hong Trang, Doan Huy Hien, and Pham Quy Ngoc, "Construction and application of an adapted rock physics template (ARPT) for characterizing a deep and strongly cemented gas sand in the Nam Con Son basin, Vietnam", Journal of Natural Gas Science and Engineering, Vol. 94, 2021. DOI: 10.1016/j. jngse.2021.104117.

[2] Djebbar Tiab and Erle C. Donaldson, Petrophysics: Theory and practice of measuring reservoir rock and fluid transport properties. Gulf Professional Publisher, 2015.

[3] P.W.M. Corbett and D.K. Potter, "Petrotyping: A basemap and Atlas for navigating through permeability and porosity data for reservoir comparison and permeability prediction", International Symposium of the Society of Core Analysts, Abu Dhabi, UAE, 5 - 9 October 2004.

[4] Ngo Thanh Vuong, Lu Dinh Vi, Nguyen Hong Minh, Hoang Manh Tan, Nguyen Manh Hung, and Le Minh $\mathrm{Vu}$, "A comparison of permeability prediction methods using core analysis data", SPE Reservoir Characterisation and Simulation Conference and Exhibition, Abu Dhabi, UAE, 14 - 16 September 2015. DOI: 10.2118/175650-MS.

[5] Tarek Ahmed, Reservoir engineering handbook. Gulf Professional Publisher, 2019.

[6] Robert L. Folk, Petrology of sedimentary rocks. Hemphill Publishing Company, 1980. 